\title{
REVERSE ALGORITHM FOR DETERMINING THE NUMBER OF CUTTING PASSES AND CUTTING CONDITIONS IN AXIAL TURNING
}

\author{
Marina Tošić, Predrag Ćosić
}

Preliminary notes

To avoid production of low quality products and reduce unnecessary time wastage, algorithms for decision making are widely used in process planning. Usually decision of selecting cutting conditions (depth of cut, feed and cutting speed) is made by experience or using handbooks. Much effort during years was invested in finding optimizing algorithms for metal cutting processes. Algorithm given by G. Halevi does not include specific tool or machine for machining process and that is why it is called reverse algorithm. Taking in consideration boundary values of cutting conditions and their effects on surface roughness, algorithm finds maximum values of cutting conditions, giving preference to the feed rate and thus minimizing the number of cutting passes. Proposed algorithm was explained by data flow implemented in software package MATLAB and tested on the example of axial turning. The obtained results were compared to recommendations retrieved from Iscar's catalog and show that algorithm is suitable for determining appropriate number of cutting passes and cutting conditions. This paper is a contribution to the automated algorithms for decision making in process planning.

Keywords: reverse algorithm, cutting conditions, axial turning

\section{Obrnuti postupak za određivanje broja prolaza i parametara obrade kod uzdužnog tokarenja}

Prethodno priopćenje

Kako bi se smanjila proizvodnja škarta i nepotrebno rasipanje vremena, algoritmi za donošenje odluka koriste se kod projektiranja tehnoloških procesa. Odabir parametara obrade (dubine reza, posmaka i brzine) uobičajeno se donosi na temelju iskustva ili upotrebom priručnika. Tijekom godina mnogo truda je uloženo u cilju pronalaska optimalnih algoritama za obradu metala. Algoritam koji je predložio G. Halevi ne uzima u obzir zadani alat ili stroj te se zbog toga naziva obrnutim postupkom. Uzimajući u obzir granične vrijednosti parametara obrade i njihov utjecaj na površinsku hrapavost, algoritam pronalazi maksimalne vrijednosti parametara, dajući prednost posmaku i time reducirajući broj prolaza kod obrade. Predloženi algoritam je prikazan pomoću dijagrama, implementiran u softverski paket MATLAB i testiran na primjeru uzdužnog tokarenja. Dobiveni rezultati su uspoređeni s preporukama iz Iscarovog kataloga te upućuju na to da je algoritam primjeren za određivanje broja prolaza i parametara obrade. Ovaj članak je doprinos automatiziranim algoritmima za donošenje odluka koji se koriste kod projektiranje tehnoloških procesa.

Ključne riječi: obrnuti postupak, parametri obrade, uzdužno tokarenje

\section{Introduction}

Having in mind that process planning is a multidisciplinary branch with production time as a primary organization measure, today's process planners are faced with constant changes in the market in terms of quality, technological improvements and user's demands.

Determination of a proper set of cutting conditions for each machining operation - roughing or finishing operation requires foreknowledge and certain level of engineering experience. Therefore, scientists have invested much effort for developing appropriate algorithms for decision making in process planning.

Regarding the high cost of machines and tools, the aim is to produce required part in one machining operation. It is well known that roughing operation has a primary objective to remove as much as possible material from the workpiece for as short as possible machining time, but with minor concern for the quality of the machining. For this reason, very often a roughing operation is not sufficient and the semi-finish and finish operations are needed in order to produce quality part and meet all drawing specifications.

Economical constraints are not the only one to be considered in selection of the optimal cutting conditions. For all machining processes, and so for turning as well, the easiest way to improve productivity is by increasing depth of cut, feed rate, or cutting speed. Unfortunately, due to inaccuracies that occur if technological constraints are exceeded, that cannot be always achieved.
Understanding the importance of choosing optimum cutting conditions in turning, G. Halevi [1] and others $[2 \div 6]$ have developed optimization models and algorithms to satisfy economic or productivity criteria. It is clear from the works $[1 \div 6]$ that prior to optimization procedure, the influence of various constraints on the final part shape has to be considered and then a series of experiments has to be conducted to estimate the effect of cutting conditions on surface roughness.

After examination of constraints, the chosen boundary values of cutting conditions determine the number of steps in the algorithm. Halevi's theory [1] is called reversed algorithm because it firstly takes into account value of depth of cut (total amount of material that needs to be removed) and material specification (hardness, surface roughness), retrieves from tables (Tab. 1 and Tab. 2) maximum working boundary values of cutting conditions and then gives optimum number of cutting passes due to selected cutting conditions (Fig. 2).

This paper points out the benefits of using algorithms for decision making in process planning and gives proposition how to reduce a planning time using simulation software.

\section{Definition of cutting conditions boundaries}

Based on metal cutting theories, it is known that there are minimum and maximum values for depth of cut, feed rate and cutting speed [1]. Cutting conditions may be specified according to hardness of materials and roughness of the surface of a workpiece [7]. 
As every cutting operation leaves its marks on the surface of the machined workpiece, it is important to understand consequences of exceeding cutting conditions.

Cutting force depends on torsion stress in the part, gripping forces, part deflection, maximum torque and depth of cut.

Depth of cut is predetermined by the workpiece geometry and final part shape. It depends on chatter, part length, gripping location, chucking type and part specifications. In roughing operations, the highest possible material removal rate is desired. In the finishing cut, depth is set to achieve the final part dimensions with a single pass removing the excessive material left after roughing. Depth of cut is one of the most influential conditions on making decision in operation selection. Below a certain depth of cut, instead of forming chips, the metal compresses and springs back when the tool has passed. Cuts of very low depth of cut cause instabilities that are explained by friction forces between tool and material or by the fact that even low amplitude vibrations cause separation of contact between tool and material. It was found [1] that the tendency to vibrate increases with depth of cut and that critical maximum depth of cut varies from machine to machine.

Feed rate depends on surface finish, tool constraints, cutting forces, maximum torque and depth of cut. Problems occur when the feed rate is very low and as a result occurs abrasive forming. On the contrary, above a certain value of feed rate, the tool wear process changes and the crater wear becomes the dominant factor instead of the flank wear. Similar as with depth of cut, some experiments indicate [1] that vibrations tend to increase with low feed rate.

Cutting speed is primarily determined by chosen tool, machine power, available speeds of the machine, cutting forces, part material, feed rate and depth of cut. Analyzing the influence of cutting speed it was found [1] that above a certain cutting speed the temperature becomes so high, that the tool wear mechanism changes from abrasive to diffusion wear, which imposes an upper limit to cutting speed. With low cutting speed and low temperature chip formation, small fragments escape from chip and lodge in the contact area between tool and workpiece. High forces in this area are causing the effect called BUE (built up edge) because the particles of workpiece become pressure welded to the cutting edge of tool. In order to avoid the BUE effect, cutting speed has to be limited.

\subsection{Analysis of boundary limit strategy}

Operation selection should be based upon the capabilities of the basic process used and its boundary limits that consist of technological, part, material, machine, tool and user constraints. Proposed algorithm first selects technical constraints as boundary limits and then selects working point regarding economic considerations.

Regarding technological limits, which are based on experiments conducted [1] on workpiece material and cutting tool, boundaries of minimum and maximum values of cutting conditions are indexed as followed:

$a_{t \max }, a_{t \min }, f_{t \max }, f_{t \min }, v_{t \max }, v_{t \min }$
Studying part constraints - dimensional tolerances, geometrical tolerances, and surface roughness in order to meet all drawing specifications has resulted with the following boundaries: $a_{s \max }, v_{s \max }, f_{s \max }$.

Similar boundaries have resulted after analyzing the influence of cutting conditions on material $\left(a_{h \max }, v_{h \text { max }}\right)$ and machines $\left(a_{v \max }, a_{v \min }, f_{v \min }, v_{v \max }\right)$, where are given recommended boundary values for depth of cut and feed:

$a_{v \min }=0,15 \mathrm{~mm}<a<a_{v \max }=7 \mathrm{~mm}$

$f_{v \min }=0,04 \mathrm{~mm} / \mathrm{rev}$

Boundary limit values given by tools constraint are indexed as $a_{k \max }, f_{k \max }, v_{k \max }$ and demands imposed by users as $a_{u \max }, f_{u \max }$. [1]

Regarding tool constraints, recommendations are to select maximum value of feed rate in the range from 0,5 $\mathrm{mm} / \mathrm{rev}$ to $0,8 \mathrm{~mm} / \mathrm{rev}$ for a cutting speed of $150 \mathrm{~m} / \mathrm{min}$ [1].

Considering the fact that the machine rigidity and tool material are constantly improving, these values should be continuously updated. If no other values are available, it is recommended [1] to use the value of $400 \mathrm{~m} / \mathrm{min}$ as upper limit and $60 \mathrm{~m} / \mathrm{min}$ as lower limit on components with carbide tool.

In the end, the evaluated constraints have given the list of maximum and minimum boundary values regarding cutting conditions. For the entire group representatives are selected as working boundary limits [1]:

$a_{a \max } a_{a \text { min }} f_{a \text { max }} \quad f_{a \text { min }} \quad v_{a \text { max }} \quad v_{a \text { min }}$

i.e., the value of $a_{a \max }$ is minimum value that represents the group of maximum boundary values $\left(a_{t \max }, a_{v \max }\right.$, $a_{h \max }, a_{s \max }, a_{k \max }$ and $\left.a_{u \max }\right)$ and the value of $a_{a \text { min }}$ is maximum value that represents group of minimum boundary values $\left(a_{t \min }, a_{v \min }\right)$.

\subsection{Surface finish due to cutting conditions}

Effect of cutting conditions on the accuracy of surface finish and tolerances must be considered. Surface finish is a widely used index of product quality and in most cases a technical requirement for mechanical products [8]. Achieving the desired surface quality is of great importance for the functional behavior of a part.

Approaches for determination of surface finish can be categorized in four groups [8]:

1) approaches that are based on machining theory to develop analytical models and/or computer algorithms to represent the machined surface;

2) approaches that examine the effects of various factors through the execution of experiments and the analysis of the results;

3) approaches that use designed experiments; and

4) artificial intelligence (AI) approaches.

The reason why designed experiments (c) were classified under a different category from the experimental approaches is because they constitute a systematic method concerning the planning of experiments, collection and analysis of data with nearoptimum use of available resources [8].

An ideal surface finish is difficult to obtain in most machining operations because of work material factors 
and how it interacts with the tool $[9,10]$. Work material factors that affect surface finish are BUE, damage to the surface caused by chip curling back into the work, tearing of the work surface during chip formation especially for ductile materials, cracks in the surface caused by discontinuous chip formation when machining brittle materials, and friction between the tool flank and the newly generated work surface [9].

All this work material factors are usually consequences of low and high cutting conditions. Analyzing how these consequences affect the surface finish, the solutions for avoiding them have been developed.

The BUE effect can be avoided by increasing cutting speed, but also burn marks might appear on the machined surface. This leads to the conclusion that feed marks and tool geometry are influential factors that cannot be isolated from the effects of cutting speed on surface finish. As tool wear increases gradually during cutting operations, its shape is being transferred on machining surface, causing a change in surface roughness. That indicates that the main cause of surface roughness comes from the feed tool marks that are regularly placed and theoretically analyzed.

In turning, surface roughness can be theoretically calculated with the equation:

$R a=\frac{f^{2}}{32 r}(\mu \mathrm{m})$

where $r$ represents tool nose radius $(\mathrm{mm})$ and $f$ is feed rate $(\mathrm{mm} / \mathrm{rev})$. The equation shows that to improve the surface roughness, feed rate need to be decreased, and nose radius should be increased.

However, a large radius might cause chatter, so the radius should be limited. Limiting tool nose radius in the range of $0,4 \div 1,6 \mathrm{~mm}$ (to avoid chatter) and adding safety factor of 0,8 , the following equations for selecting a feed rate that will produce specified $R a$ are recommended [1]:

$$
f=0,1 R a \text { for } R a \leq 3,2
$$

$$
f=0,18(R a)^{2} \text { for } R a>3,2
$$

These equations give the value of $f_{s} \max$ for finish cuts, while the value of $f_{a \max }$ will be used for rough cuts. The results of the analysis have shown that the depth of cut does not have direct influence on surface roughness, but it has to be limited in order to avoid deformation of workpiece, chatter, deflection and many other factors that are consequence of increased cutting force due to increased depth of cut.

It is proposed [1] to limit the depth of cut $a_{s \max }$ as a function of material hardness and surface roughness:

$a_{s \max }=\frac{32 R a}{H B^{0,8}}(\mathrm{~mm})$

where $H B$ is the value of material hardness in Brinells.

Eq. (4) is a simplified equation and it relates depth of cut, tool nose radius, surface roughness and many practical recommendations of tool manufacturers and practitioners [1]. Also, it gives the value $a_{s} \max$ for finish cuts, while $a_{a \max }$ will be used for rough cuts.

\section{Reverse algorithm procedure}

Traditionally, selection of cutting conditions for metal cutting has been decided by operator and the quality of produced part depended on their experience. Using modern technology and expensive machines, task of determining cutting conditions has been transferred to engineers with responsibility of selecting optimum cutting conditions.

Techniques for optimizing cutting conditions can be divided into classical and modern techniques [11]. Classical techniques for optimizing machining conditions are derived from Taylor's tool life equation and include geometric programming, linear programming, goal programming, sequential unconstrained minimization technique and dynamic programming [11]. Modern techniques include fuzzy logic, scatter search technique, genetic algorithm, Taguchi technique and response surface methodology [11].

\subsection{Basis of the algorithm}

Proposed algorithm for determining cutting operations is suitable for all metal cutting processes. It is based on minimizing number of cutting passes while finding values of cutting conditions as high as possible, giving preference to the feed according to well-known optimization strategies.

Table 1 Feed and maximum depth of cut as a function of surface

\begin{tabular}{|c|c|c|c|c|c|c|c|c|}
\hline \multicolumn{7}{c|}{$a_{s \max }(\mathrm{mm})$} \\
\hdashline $\begin{array}{c}\mid c \\
\text { Brinell hardness }(\mathrm{HB}) \\
(\mu \mathrm{m})\end{array}$ & $\begin{array}{c}f_{s \max } \\
(\mathrm{mm} / \mathrm{rev})\end{array}$ & 100 & 200 & 250 & 300 & 350 & 400 \\
\hline 0,80 & 0,08 & 0,64 & 0,37 & 0,31 & 0,26 & 0,24 & 0,22 \\
\hdashline 1,00 & 0,10 & 0,80 & 0,46 & 0,39 & 0,33 & 0,30 & 0,27 \\
\hdashline 2,00 & 0,20 & 1,61 & 0,92 & 0,77 & 0,67 & 0,59 & 0,53 \\
\hline 3,00 & 0,30 & 2,41 & 1,38 & 1,16 & 1,00 & 0,89 & 0,80 \\
\hline 4,00 & 0,36 & 3,22 & 1,85 & 1,54 & 1,34 & 1,18 & 1,06 \\
\hdashline 5,00 & 0,40 & 4,02 & 2,31 & 1,93 & 1,67 & 1,48 & 1,33 \\
\hdashline 6,00 & 0,44 & 4,82 & 2,77 & 2,32 & 2,00 & 1,77 & 4,59 \\
\hline 7,00 & 0,48 & 5,63 & 3,23 & 2,70 & 2,34 & 2,07 & 1,86 \\
\hdashline 8,00 & 0,51 & 6,43 & 3,69 & 3,09 & 2,67 & 2,36 & 2,12 \\
\hdashline 9,00 & 0,54 & 7,23 & 4,15 & 3,48 & 3,00 & 2,66 & 2,39 \\
\hdashline 10,00 & 0,57 & 8,04 & 4,62 & 3,86 & 3,34 & 2,90 & 2,65 \\
\hdashline 11,00 & 0,60 & 8,84 & 5,08 & 4,25 & 3,67 & 3,20 & 2,92 \\
\hdashline 12,00 & 0,62 & 9,65 & 5,54 & 4,63 & 4,01 & 3,50 & 3,18 \\
\hdashline 13,00 & 0,65 & 10,45 & 6,00 & 5,02 & 4,34 & 3,80 & 3,45 \\
\hline
\end{tabular}

Values of maximum depth of cut $a_{s \text { max }}$ and feed rate $f_{s \text { max }}$ as a function of surface roughness are shown in Tab. 1 and values of $a_{s}$ min as a function of feed and depth of cut in Tab. 2.

Developed depth of cut boundaries (Fig. 1) that are used in the algorithm are:

- $a_{a \max }-$ maximum allowed depth of cut

- $a_{c}$ max - maximum computed depth of cut of a segment, when using minimum feed rate, computed by: 


$$
a=\frac{F_{z}}{C_{p} \cdot f^{v}}
$$

where $F_{z}$ is total cutting force $(\mathrm{N}), C_{p}$ is specific cutting force (for medium steel -220 ) and $f$ is feed rate with exponent $v=0,75$.

Table $2 a_{s \min }$ as a function of feed and depth of cut [1]

\begin{tabular}{|c|c|c|c|c|c|c|}
\hline \multicolumn{7}{|c|}{ Depth of cut (mm) } \\
\hline $\begin{array}{c}\text { Feed } \\
(\mathrm{mm} / \mathrm{rev})\end{array}$ & 1,00 & 1,50 & 2,00 & 2,50 & 3,00 & 3,50 \\
\hline 0,10 & 0,10 & 0,13 & 0,15 & 0,20 & - & - \\
\hline 0,20 & 0,15 & 0,17 & 0,19 & 0,23 & 0,28 & - \\
\hline 0,30 & 0,17 & 0,20 & 0,25 & 0,30 & 0,39 & 0,40 \\
\hline 0,40 & - & 0,28 & 0,30 & 0,38 & 0,46 & 0,50 \\
\hline 0,50 & - & 0,32 & 0,36 & 0,45 & 0,54 & 0,60 \\
\hline 0,60 & - & - & 0,41 & 0,52 & 0,62 & 0,70 \\
\hline 0,70 & - & - & 0,46 & 0,58 & 0,70 & 0,80 \\
\hline 0,80 & - & - & 0,51 & 0,64 & 0,77 & 0,90 \\
\hline 0,90 & - & - & - & 0,81 & 0,97 & 1,10 \\
\hline 1,00 & - & - & - & 1,00 & 1,20 & 1,40 \\
\hline \multicolumn{7}{|c|}{ Depth of cut (mm) } \\
\hline $\begin{array}{c}\text { Feed } \\
(\mathrm{mm} / \mathrm{rev})\end{array}$ & 5,00 & 6,00 & 7,00 & 8,00 & 9,00 & 10,00 \\
\hline 0,10 & - & - & - & - & - & - \\
\hline 0,20 & - & - & - & - & - & - \\
\hline 0,30 & 0,61 & 0,74 & 0,86 & - & - & - \\
\hline 0,40 & 0,76 & 0,92 & 1,06 & 1,24 & 1,37 & - \\
\hline 0,50 & 0,90 & 1,08 & 1,26 & 1,46 & 1,61 & 1,00 \\
\hline 0,60 & 1,03 & 1,24 & 1,45 & 1,65 & 1,85 & 2,00 \\
\hline 0,70 & 1,16 & 1,39 & 1,62 & 1,85 & 2,08 & 2,30 \\
\hline 0,80 & 1,28 & 1,54 & 1,79 & 2,05 & 2,30 & 2,50 \\
\hline 0,90 & 1,62 & 1,98 & 2,27 & 2,59 & 2,92 & 3,20 \\
\hline 1,00 & 2,00 & 2,40 & 2,80 & 3,20 & 3,60 & 4,00 \\
\hline
\end{tabular}

If $a_{c \max }>a_{a \max }$ then $a_{c \max }=a_{a \max }$
- $a_{a \min }-$ absolute minimum required depth of cut

- $a_{c \min }-$ minimum computed depth of cut of a segment, when using maximum feed rate, computed by (5)

- $a_{s \max }$ - maximum depth of cut that will produce the specified surface roughness, computed by (4) or retrieved from Tab. 1

- $a_{s \text { min }}$ - minimum depth of cut that must be used in order to remove inaccuracies of the previous cutting pass, or inaccuracies of the raw material - retrieved from Tab. 2

- $a_{\mathrm{s}}$ - previous depth of cut that results with $a_{s \min }$ value - retrieved from Tab. 2 (step 4 in algorithm)

- $a_{n}$-amount of material to be removed, computed by:

$a_{n}=W_{G}-W$

where $W_{G}$ is dimension of any intermediary cut of raw material and $W$ is required dimension of the finished part. In turning, the dimensions of $W_{G}$ and $W$ are divided with two.

Fig. 1 shows that the most economic method of machining a part is using a single pass, i.e. depth of cut $a_{n}$. Considering boundaries and constraints that cannot always be fulfilled, and the following algorithm proposes steps for possible solutions (Fig. 2).

\subsection{Model of the algorithm}

The algorithm contains 13 interdependent steps and as a result gives solution of one, two or three cutting passes with suitable cutting conditions (Fig. 2).

As a primary step, it is important to input correct values of working boundary limits for cutting conditions, required values of surface roughness $(R a)$ and material hardness $(H B)$, value of Young's elasticity module $(E)$ and initial and requested (finish) value of workpiece diameter.

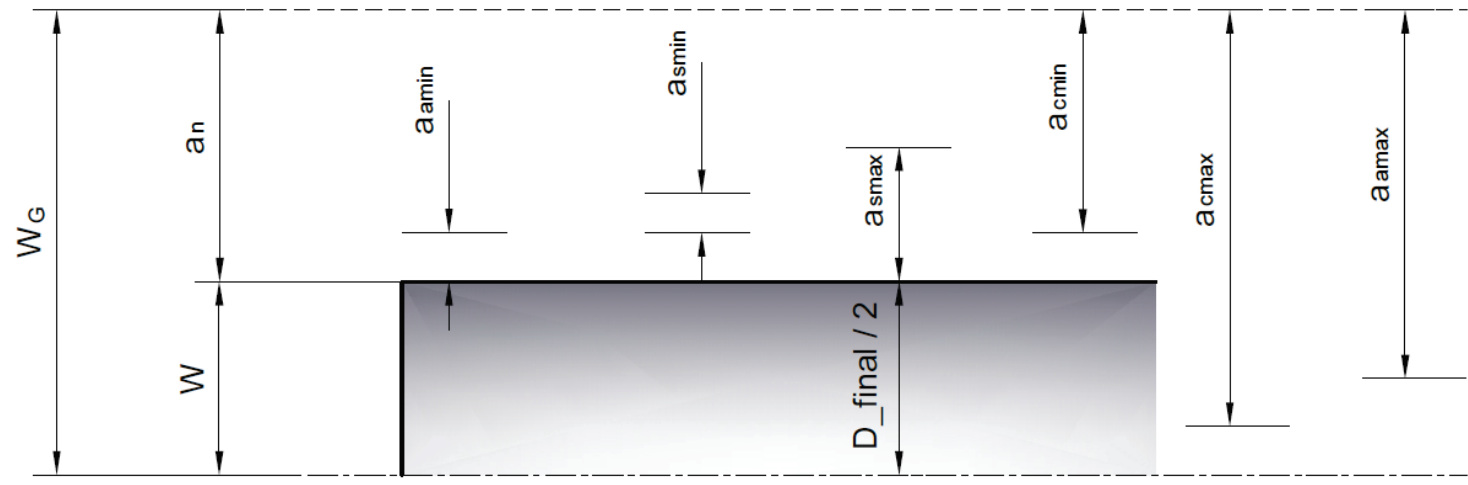

Figure 1 Boundaries in part segment

To find the solution those results with one cutting pass, the algorithm first takes from Tab. 1 the value of depth of cut $a_{s \text { max }}$ as a function of $R a$ and $H B$ (step 1). That value is compared to the value of $a_{n}$, that is computed by (6) (step 2). If the value of $a_{n}$ is smaller than the value of $a_{s \text { max }}$, one cutting pass can produce required dimension of the part. Finish depth of cut is the value of $a_{n}$ and finish feed rate is taken from Tab. 1 (step 10). In case of raw material (cast or forged) it is recommended
[1] to check if the value of $a_{n}$ is higher than the value of $a_{s \text { min }}$ in order to produce a good part.

If the value of $a_{n}$ is higher than $a_{s \max }$, it is necessary to calculate $a_{s \text { min }}$ (step 3 ). After calculating $a_{s \text { min }}$, from Tab. 2 is retrieved the value of $a_{s}$ as a function of the highest possible feed rate that gives the value of $a_{s}$ min (step 4). The number of maximum possible cutting passes $P_{G}$ is compared to the value of $a_{s}$ (step 6). If that value is smaller than or equal to the value of $a_{s}$, two cutting passes can produce the segment (step 11). 
Finish cut results with feed rate taken from Tab. 1 and depth of cut $a_{0}$ calculated as a sum of $a_{a \text { min }}$ and a new value of $a_{s} \min$ marked as $Q$ (taken from Tab. 2 as a function of $P_{G}$ and a maximum feed rate that complies with the value of $a_{s \mathrm{~min}}$ ). Rough cut results with the feed rate taken from Tab. 2 and the depth of cut $a_{1}$ calculated as a difference between $a_{n}$ and $a_{0}$.

Also, solution of two cutting passes can be obtained by steps 7, 8, 9 and 13 . If the value of maximum possible cutting passes $P_{G}$ is higher than the value of $a_{s}$, it is necessary to calculate possible number of cuts $B$ that will be rounded to closer upper integer $B_{i}$. The number of cutting passes will be calculated as a sum of $B_{i}$, semi- finish and finish cut (step 7). Distribution of depth of cut $a_{p}$ is computed in step 8 and compared to $a_{c \text { min value (step }}$ 9 ). If the value of $a_{p}$ is higher than the value of $a_{c \text { min }}, B_{i}-1$ rough cut will result with depth of cut $a_{p}$. Feed rate and number of maximum possible cutting passes $P_{G}$ will be calculated by step 13 that leads to step 11 and gives solution of two cutting passes.

Finally, solution of three cutting passes will be obtained if the value of $a_{p}$ is smaller than or equal to the value of $a_{c \text { min }}$ (step 9). Rough cut $B_{i}-1$ will result with the depth of cut $a_{c \text { min }}$ and the feed rate $f_{a \text { max }}$. The last rough cut $a_{1}$, as well as the semi-finish and finish cut will be calculated by step 12 .

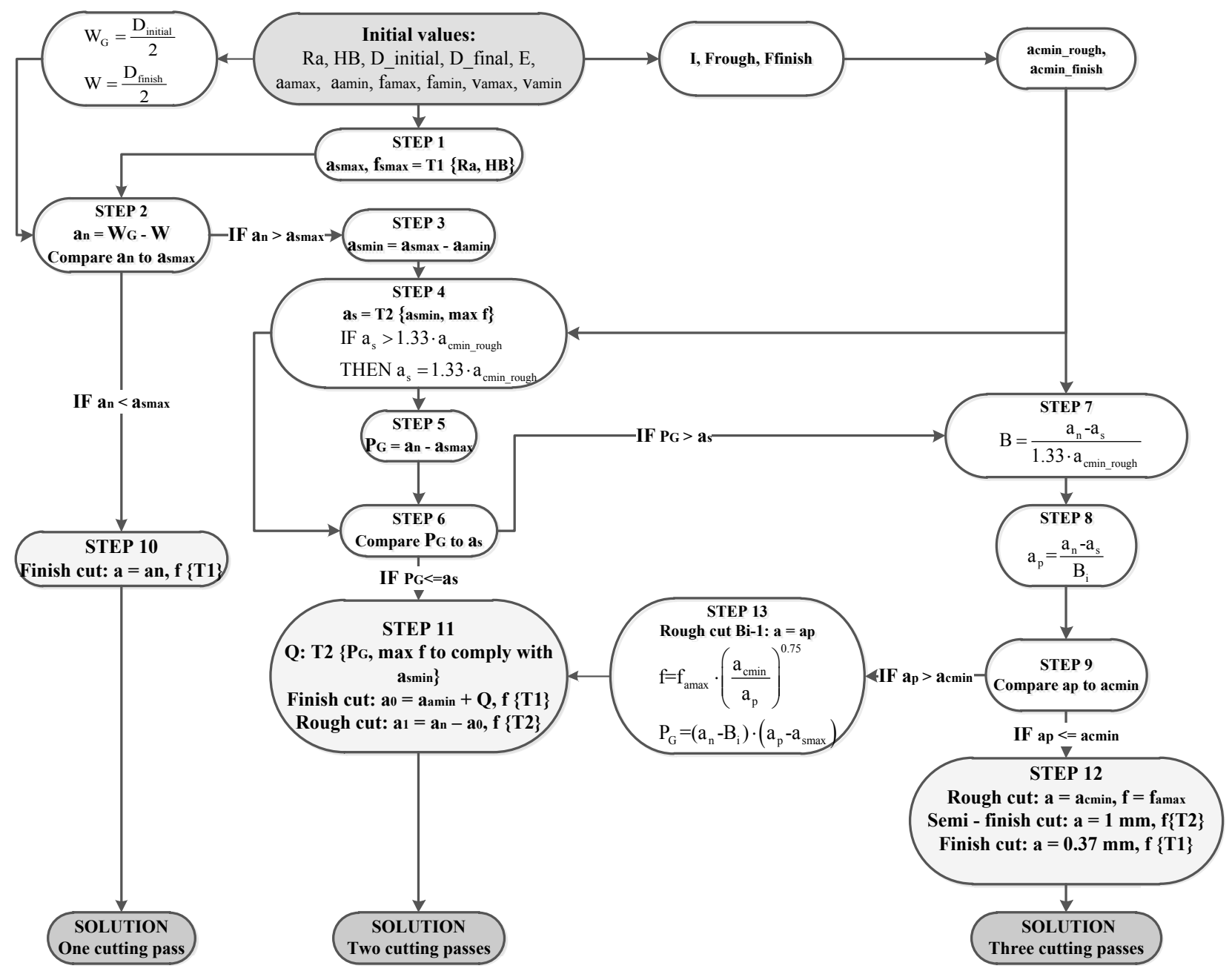

Figure 2 Data flow of the algorithm for determining number of cutting operations

\subsection{Example for algorithm testing}

Optimization procedure discussed in previous chapter was tested on the example shown in Fig. 3.

Given material is SAE 1020 (S275JR according to EN 10025 (DIN 17100)), with material hardness $200 \mathrm{HB}$ and Young's elasticity module $E=2,2 \times 10^{5} \mathrm{MPa}$. Initial $D$ is $\varnothing 50 \mathrm{~mm}$, and has to be machined on value of $\varnothing 45 \mathrm{~mm}$.

It is assumed [1] that the allowed deflection in the rough cut is $\delta=0,1 \mathrm{~mm}$, and in the finish cut $20 \%$ of the tolerance $\delta=0,08 \times 0,2=0,016 \mathrm{~mm}$.

The allowable acting forces on the part during machining are computed as a beam at one hand and loaded at the other.

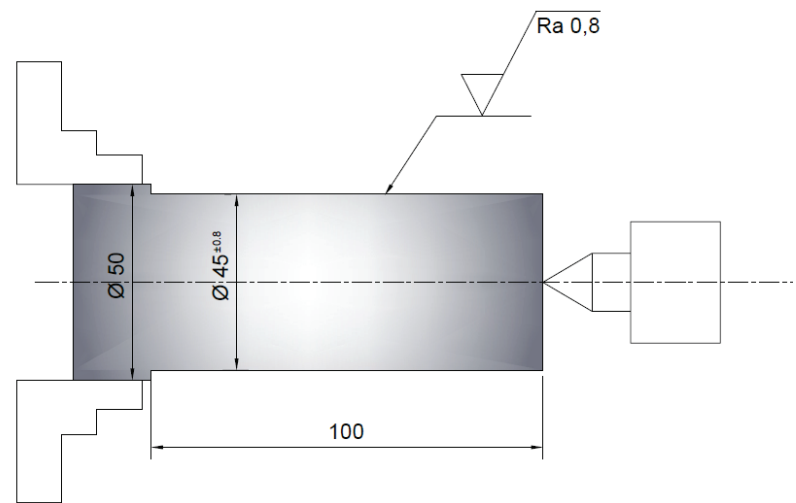

Figure 3 Example for algorithm testing 
The search for the optimum cutting conditions has started by submitting initial values in the algorithm implemented by software package MATLAB. Following explained steps, algorithm has proved that the required surface roughness $R a=0,8$ for the specified material of hardness $H B=200$ can be achieved in three cutting passes (Fig. 4).

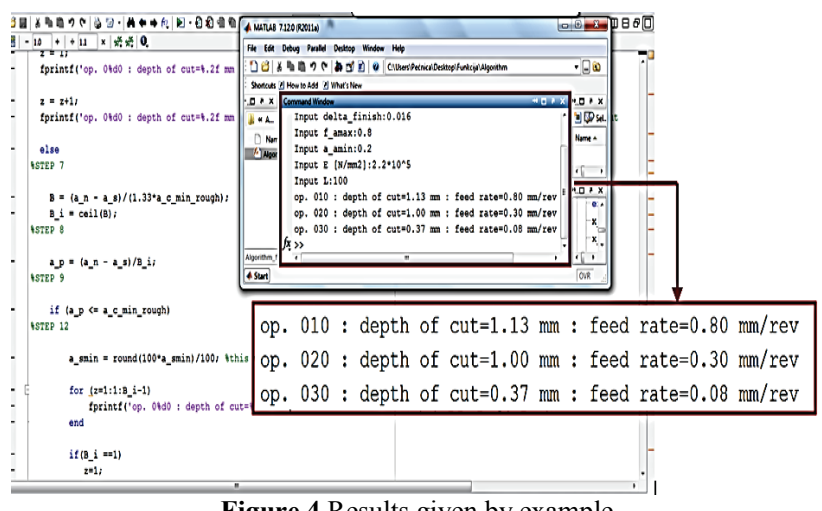

Figure 4 Results given by example

To verify the solution of implemented algorithm, the input values are entered in Iscar handbook [12] that also recommends the number of cutting passes and tools due to selected material, surface finish, and material hardness (Fig. 5). Required depth of cut was entered as the value of $a_{n}$ - total amount of material that has to be removed.

The handbook also recommended three cutting passes, but it distributed $a_{n}$ on equal depth of cut in all passes. Knowing that values given by handbook are medium values of cutting conditions with economic constraint as basis, those values are usually used in machining. Values given by algorithm are result of maximum cutting condition values with primary consideration on technological constraints.

\section{Conclusion}

Because of the various combinations of different cutting conditions due to economic or technological constraints, determination of the cutting conditions is a complex problem in the process planning. Usually, selection of cutting conditions is chosen after selecting proper tools and machines for required workpiece.

As every plant has limited machines, the maximum cutting force of each machine is known and that imposes the maximum depth of rough cut.

Serious process planners will always consider various methods in order to reduce planning time and improve manufacturing. That is why it is important to understand decision making algorithms as key factors in automation of process planning.

All conclusions can be summarized as follows:

- Due to proposed method in this article, every plant can use this decision making algorithm substituting their values of technological, part, material, machine or tool constraints in given tables.

- This paper has shown that reverse procedure can lead to determining the number of cutting passes and cutting conditions.

- Used approach should greatly minimize process planning time and thus lead to savings.

- The focus of the future work will be to research the possibility of application of this algorithm in a production of large series of shafts on $\mathrm{CNC}$ machines, which would be a step to CAPP.

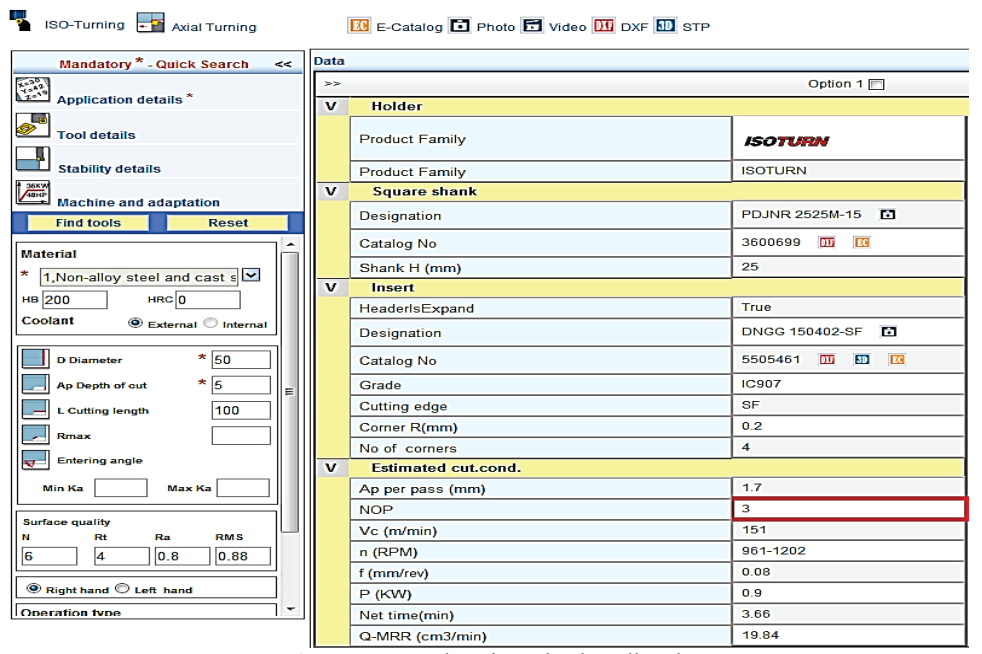

Figure 5 Results given by handbook

\section{Acknowledgements}

This paper is a part of the scientific projects (20072009) titled Process Production Impacts to the Competitive and Sustainable Development 120-15217813116 (the main researcher Prof. Predrag Cosic, PhD) funded by the Ministry of Science and Technology of the Republic of Croatia. We express gratitude for the financial support to these projects.

\section{$5 \quad$ References}

[1] Halevi, G. Process and Operation Planning, Kluwer Academic Publishers, Dordrecht, 2003. pp. 147-172. DOI: 10.1007/978-94-017-0259-1_8

[2] Lee, B. Y., Tarng, Y. S. Cutting-parameter selection for maximizing production rate or minimizing production cost in multistage turning operations. // Journal of Materials Processing Technology. 105, 1(2000), pp. 61-66. DOI: 10.1016/S0924-0136(00)00582-3 
[3] Meng, Q.; Arsecularatne, J. A.; Mathew, P. Calculation of optimum cutting conditions for turning operations using a machining theory. // International Journal of Machine Tools \& Manufacture. 40, 2(2000), pp. 1709-1733. DOI: 10.1016/S0890-6955(00)00026-2

[4] Satishkumar, S.; Asokan, P.; Kumanan, S. Optimization of depth of cut in multi-pass turning using nontraditional optimization techniques // The International Journal of Advanced Manufacturing Technologies. 29, 3-4(2006), pp. 232-238.

[5] Sardi-as, R. Q.; Santana, M. R.; Brindis, E. A. Genetic algorithm-based multi-objective optimization of cutting parameters in turning processes. // Engineering Applications of Artificial Intelligence. 19, 2(2006), pp. 127-133. DOI: 10.1016/j.engappai.2005.06.007

[6] Wang, J.; Kuriyagawa, T.; Wei, X. P.; Guo, D. M. Optimization of Cutting Conditions for Single Pass Turning Operations Using a Deterministic Approach. // International Journal of Machine Tools and Manufacture. 42, 9(2002), pp. 1023-1033. DOI: 10.1016/S08906955(02)00037-8

[7] Asiltürk, I.; Akkuş, H. Determining the effect of cutting parameters on surface roughness in hard turning using the Taguchi method. // Measurement. 44, 9(2011), pp. 16971704. DOI: 10.1016/j.measurement.2011.07.003

[8] Benardos, P. G.; Vosniakos, G.-C. Predicting surface roughness in machining: a review. // International Journal of Machine Tools \& Manufacture. 43, 8(2003), pp. 833844. DOI: $10.1016 / S 0890-6955(03) 00059-2$

[9] Taha, Z.; Lelana, H.-K.; Aoyama, H. Insert geometry effects on surface roughness in turning process of AISI D2. // Journal of Zhejiang University - SCIENCE A. 12, 11(2010), pp. 966-971. DOI: 10.1631/jzus.A1001356

[10] Groover, M. P. Fundamentals of Modern Manufacturing, Materials, Processes and Systems. // Student Edition, John Wiley \& Sons, Hoboken, 2007

[11] Aggarwal, A.; Singh, H. Optimization of machining techniques - A retrospective and literature review. // Sādhanā. 30, 6(2005), pp. 699-711. DOl: 10.1007/BF02716704

[12] Iscar tool advisor, www.iscar.com/ita/ (26.04.2012)

\section{Authors' addresses}

\section{Marina Tošić}

University of Zagreb

Faculty of Mechanical Engineering and Naval Architecture Ivana Lučića 5

10000 Zagreb, Croatia

Tel. 01/61 68441

E-mail: marina.tosic@fsb.hr

\section{Predrag Ćosić}

University of Zagreb

Faculty of Mechanical Engineering and Naval Architecture Ivana Lučića 5

10000 Zagreb, Croatia

Tel. 01/61 68340

E-mail: predrag.cosic@fsb.hr

\section{Appendix - part of an algorithm code}

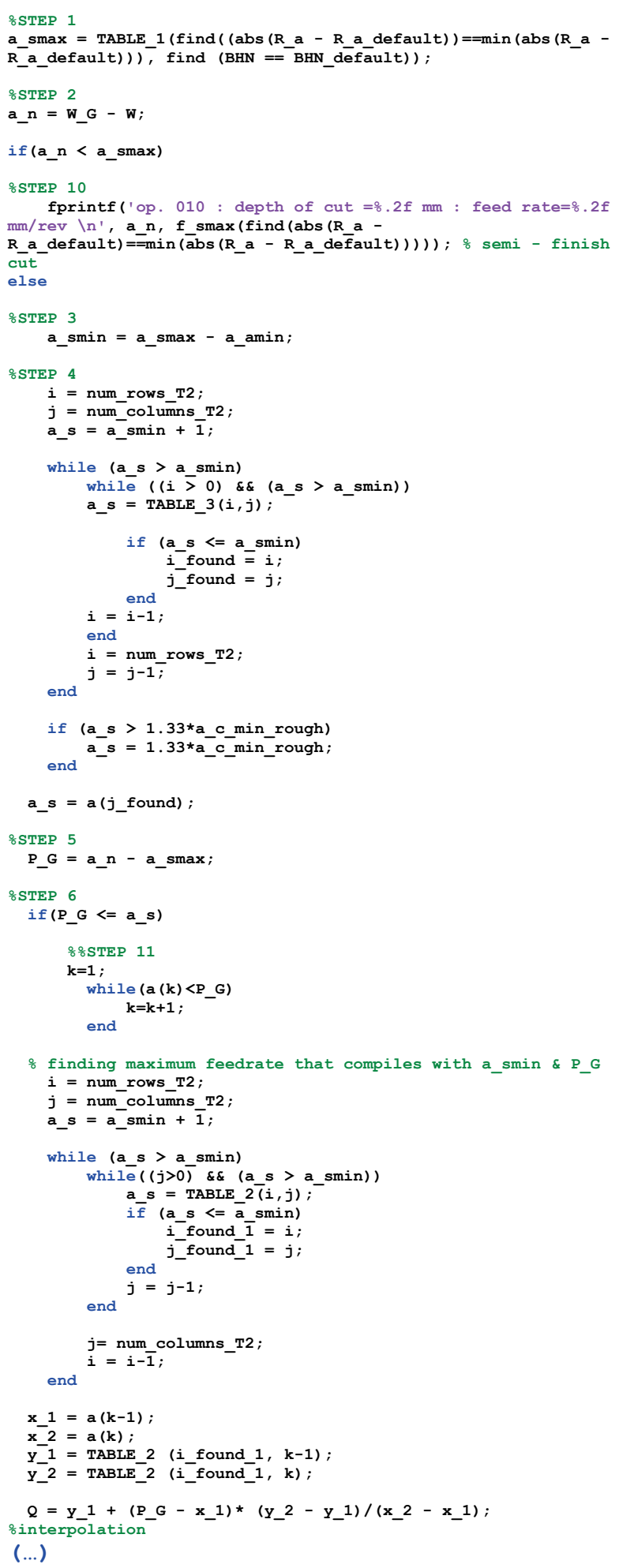

